\title{
Anterior cruciate ligament injury: towards a gendered environmental approach
}

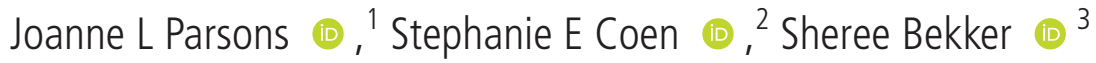

${ }^{1}$ College of Rehabilitation Sciences, University of Manitoba, Winnipeg, Manitoba, Canada

${ }^{2}$ School of Geography, University of Nottingham, Nottingham, UK ${ }^{3}$ Department for Health, University of Bath, Bath, UK

\section{Correspondence to} Dr Joanne L Parsons, College of Rehabilitation Sciences, University of Manitoba, Winnipeg, Manitoba, Canada; joanne.parsons@umanitoba.ca

Accepted 22 February 2021 Published Online First 10 March 2021

\section{Check for updates}

(c) Author(s) (or their employer(s)) 2021. No commercial re-use. See rights and permissions. Published by BMJ.

To cite: Parsons JL, Coen SE, Bekker S. Br I Sports Med 2021:55:984-990

\section{ABSTRACT}

Background The anterior cruciate ligament $(A C L)$ injury rate for girls/women has not changed in over 20 years, and they remain 3-6 times more likely to experience injury compared with boys/men. To date, ACL injury prevention and management has been approached from a sex-based biological point of view which has furthered our understanding of injury risk factors, mechanisms, and prevention and rehabilitation programmes. However, the traditional sex-based approach does not take into account the growing recognition of how sex and gender (a social construct) are 'entangled' and influence each other.

Objective This paper discusses the curious absence of gender as an influencer in the dialogue surrounding $A C L$ injuries. We propose adding gender as a pervasive developmental environment as a new theoretical overlay to an established injury model to illustrate how gender can operate as an extrinsic determinant from the presport, training and competition environments through to $A C L$ injury and the treatment environment.

Approach We draw on social epidemiological theories of the embodiment of gender and health to provide plausible examples of how gender may influence ACL injury, and demonstrate the opportunity for new, interdisciplinary research in the field.

Conclusion Over 20 years of research has failed to decrease the $A C L$ injury rate disparity between girls/ women and boys/men. Embedding gender in the study of $\mathrm{ACL}$ injury will heighten awareness of possible influences outside the traditional biological elements, challenge us to think about the inextricable 'entanglement' of sex and gender, and inform more effective approaches to $\mathrm{ACL}$ injury prevention and treatment.

\section{INTRODUCTION}

The sporting world was first alerted to the extent of the anterior cruciate ligament (ACL) injury problem in the 1990s. The fact that girls and women were experiencing these life-altering injuries at 3-6 times the rate of boys and men $^{12}$ caught the attention of parents and coaches, who demanded action. Researchers responded with enthusiasm; as of 15 July 2020, a PubMed search for 'anterior cruciate ligament' or 'ACL' returned over 27000 results. However, from the beginning, investigation into the injury rate disparity between women and men has focused heavily on 'sex'-based biological traits such as anatomy, physiology and hormones, ${ }^{3}$ and has not considered wider gendered social influences, aside from brief mentions in review papers. ${ }^{4-6}$ Annual ACL injury rates in the general population have remained unchanged in girls and women, while they have decreased among boys and men, ${ }^{7}$ suggesting that strictly biological explanations may be insufficient to improve outcomes for girls and women. In collegiate athletes, injury incidence has actually increased, with women experiencing higher rates than men in the same sports. ${ }^{8}$ However, ACL injuries are not limited to high level athletes; in one study, the largest difference in incidence rates between women and men was seen in recreational athletes. ${ }^{9}$ Clearly, the extensive work done to date has not been fully effective in teasing out the complex, interacting factors which contribute to these injuries in girls and women.

Improving our understanding of the ACL injury disparity between girls/women and boys/men is essential, as the acute and longer-term consequences of injury can significantly affect health. In addition to the immediate impact on physical and emotional health, experiencing an ACL injury at a young age is associated with a higher likelihood of developing early-onset osteoarthritis, and requiring a total joint arthroplasty. ${ }^{10}$ ACL injury results in only $65 \%$ of individuals returning to their preinjury level of sport, with men 1.7 times more likely than women to do so. ${ }^{4}$ As childhood and youth physical activity levels influence those in adulthood, ${ }^{11}$ the sequelae of ACL injury are lifelong and particularly concerning for women who already participate in physical activity at lower rates than men. ${ }^{12}$

Approaching ACL injury prevention and management with a strictly biological view can propagate sexism in sport with detrimental consequences for girls and women as seen in two recent cases. Based on a cross-sectional study, it was suggested that oral contraceptive pills prevent ACL injury, and should be prescribed to all young athletes. ${ }^{13}$ Methodological and ethical problems associated with those conclusions were identified ${ }^{14}{ }^{15}$; nevertheless, the original work continues to be cited. In the second case, media reported that the women's Australian Rules football league was experiencing high ACL injury rates, and the league's default response was to investigate the association with the menstrual cycle. ${ }^{16}$ Framing women's sport participation, as in these two examples, as "dangerous predominantly due to female biology"17 demonstrates how the wider gendered social context of labelling women's bodies as not being 'naturally' fit for sport strongly influences how ACL injuries have been studied. This also relies on normative assumptions of what a woman's body is or should be and does not hold space for those individuals beyond the sex binary. Fox et al put forward a compelling case that reducing women's injury risk to biological causes (eg, hormones, anatomy, physiology) fundamentally misrepresents the root cause of ACL injury, ${ }^{17}$ which is likely to be strongly influenced 
by gendered environmental disparities including access to and experiences with sport and training. As such, injury risk factors previously considered to only be intrinsic to the athlete (eg, muscle strength, body composition, skill level) conceivably contain some degree of extrinsic influence.

In this paper, we propose that gender operates as an extrinsic "pervasive developmental environment" ${ }^{18}$ present in the ACL injury cycle from presport, to training and competition, through to treatment and rehabilitation. Rather than a linear pathway, ACL injury risk can be considered cyclical, as "adaptations occur within the context of sport (both in the presence and absence of injury) that alter risk and affect aetiology in a dynamic, recursive fashion." ${ }^{19}$ We first describe and critique the current sexbased ACL injury paradigm including the traditional view of risk factors as binary (ie, intrinsic or extrinsic), the mechanism of injury, prevention programmes and injury models. We next introduce our gendered environmental approach to ACL injury as a new theoretical overlay to Meeuwisse et al's widely accepted dynamic, recursive model of aetiology in sport injury. ${ }^{19}$ We illustrate how considering gendered environmental factors can enhance our understanding of the disparate rates of ACL injury among girls/women and boys/men. By placing bodies in context, our alternative lens identifies opportunities to disrupt the ACL injury cycle and achieve more equitable outcomes for girls and women. We argue that by shifting the focus of risk from individual bodies to also include the gendered environments characterising the state of play, we are better positioned to understand the interaction of risk factors and develop interventions that can systemically change the injury landscape for all girls and women in sport.

\section{THE CURRENT ACL INJURY PARADIGM}

First, it is important to acknowledge that it is common practice in sport medicine literature related to ACL injury to use the terms sex and gender (similarly: female and women) interchangeably, without consideration or explanation as to how research participants were delineated and why this was appropriate in the given context. Because of the manner in which sport has been institutionalised, with the convention of dividing competition into binary categories of girls/women and boys/ men, athlete study participants are presumably most often classified according to their sex assigned at birth, regardless of which term is used in the manuscript. Sex refers to a complex blend of physical and physiological characteristics (eg, hormones, genes, anatomy), while gender refers to identities, roles and structures that are formed by society, which may or may not align with sex-neither of which is binary. ${ }^{20}$ Therefore, how sex and gender are constructed-or, more often, how this is not adequately accounted for or explained-in many papers related to ACL injury is largely misguided. There is an overall need for greater specificity in ACL injury research to report the sexed and/or gendered characteristics considered. While beyond the scope of the present paper, we refer the reader to other authors for guidance. ${ }^{21}$

\section{Risk factors}

Much effort has been devoted to determining factors that may identify individuals at greater risk of ACL injury, with the ultimate goal of implementing appropriate prevention programmes. Risk factors have traditionally been categorised as either intrinsic or extrinsic, meaning internal or external to the individual athlete, respectively. ${ }^{19} 22$ Typical intrinsic factors include anatomy, hormones, genetics and qualities of the neuromuscular
Table 1 A snapshot of the current binary categorisation of intrinsic and extrinsic risk factors for non-contact anterior cruciate ligament injury*

\begin{tabular}{|c|c|}
\hline Modifiable risk factors & Non-modifiable risk factors \\
\hline Environmental & Environmental \\
\hline Meteorological conditions (E) & Playing situation (E) \\
\hline Playing surface (E) & Opponent behaviour (E) \\
\hline Rules (E) & Unanticipated events during play (E) \\
\hline Referees (E) & Anatomical \\
\hline Coaching (E) & $\mathrm{Q}$ angle (I) \\
\hline Equipment & Navicular drop (I) \\
\hline Footwear (E) & Structural knee valgus (I) \\
\hline Knee braces (E) & Postural alignment (I) \\
\hline Anatomical & Notch size, ACL geometry and properties (I) \\
\hline Foot pronation (I) & Tibial slope angle (I) \\
\hline $\begin{array}{l}\text { Body composition and body mass } \\
\text { index (I) }\end{array}$ & Generalised joint hypermobility or laxity (I) \\
\hline Neuromuscular & Hormonal \\
\hline Dynamic knee valgus (I) & Menstrual phase (I) \\
\hline Muscle strength (I) & Hormone concentrations (I) \\
\hline Muscle strength ratios (I) & Demographic \\
\hline Muscle activation patterns (I) & Age (I) \\
\hline Muscle stiffness (I) & Maturation (I) \\
\hline $\begin{array}{l}\text { Physical fitness and muscle fatigue } \\
\text { (I) }\end{array}$ & Previous contralateral knee $\mathrm{ACL}$ injury (I) \\
\hline Skill level (I) & Familial history and genetics (I) \\
\hline Neuromuscular control (I) & $\operatorname{Sex}(I)$ \\
\hline Proprioception (I) & Height (I) \\
\hline Psychological (I) & Race (I) \\
\hline Personality (I) & Sports played (I) \\
\hline Stress response (I) & \\
\hline
\end{tabular}

*Table collated and modified from 92,103; and based on 31,104-107.

E, extrinsic; I, intrinsic.

system (eg, quadriceps/hamstrings ratio). Commonly listed extrinsic factors include weather conditions and the playing surface, ${ }^{22}$ essentially the material conditions of play. Table 1 provides a snapshot of the current understanding of intrinsic and extrinsic risk factors identified in the ACL literature. What is apparent from this summary is an overwhelming focus of risk at an intrinsic (individual) level, with minor environmental nods to coaching and opponent behaviour.

We suggest that the traditional binary labelling of factors as either intrinsic or extrinsic is problematic, as many seemingly intrinsic factors can be heavily influenced by environment and society. For example, muscular strength is traditionally considered an intrinsic factor, suggesting that it is the individual's responsibility to address. However, we know that the programmes and environments (eg, gyms) required to build muscular strength are heavily gendered in ways that disadvantage women's participation. ${ }^{23-26}$ During the teenage years, boys experience a muscular strength and motor performance growth spurt, while girls plateau. ${ }^{27}{ }^{28}$ Yet, in the literature, these differences are discussed mainly in relation to sex. The underlying assumption is that boys/men and girls/women are situated in equivalent training contexts, which, as mentioned above, they are likely not. It leaves open the question as to how the immediate social context of training and playing, as well as wider gender norms about girls' participation in sports and physical activity, shape girls' learnt behaviours and body movements, and whether this factors into injury risk. 


\section{Mechanism of injury}

ACL injuries can occur due to direct contact, or indirectly via a non-contact mechanism during sudden deceleration or planting a foot and changing direction. ${ }^{29}$ Contact injury rates are higher in boys and men, while non-contact mechanisms are more frequently reported in girls and women, ${ }^{8}$ perhaps partly reflecting participation in different types of sports. Multiplanar movement patterns observed at the time of non-contact injury that are thought to place high strain on the $\mathrm{ACL}^{30}$ involve multiple joints and include decreased knee flexion, excessive knee valgus, ${ }^{29}$ lateral trunk displacement and increased hip extension. ${ }^{31}$ Some research suggests differences in movement patterns which disadvantage girls and women (eg, dynamic knee valgus $^{32}$ and peak landing forces), ${ }^{33}$ but no strong evidence exists that the biomechanics at the moment of ACL injury is different between sexes. ${ }^{3435}$ If the athlete's position at the instant of injury is the same, but the rate of ACL injury in girls/women is 3-6 times higher than in boys/men, this suggests that biomechanical differences are insufficiently explanatory on their own.

\section{ACL injury prevention programs}

To improve movement control in high risk positions, many exercise-based ACL injury prevention programmes have been developed. When girls and women participate in this dedicated training, they experience a significant $67 \%$ decrease in noncontact ACL injuries. ${ }^{36}$ While found to be highly efficacious when delivered in a structured, supervised manner as part of a research study, ACL injury prevention programmes have suffered from low levels of adherence once that structure disappears. ${ }^{37}$ Perhaps this is not surprising, given that one type of activity important for effective ACL injury prevention is strength training. ${ }^{38}$ Improving neuromuscular strength is essential, as lower levels of hip abduction and external rotation strength are predictors of increased ACL injury risk in both women and men. ${ }^{39}$ However, girls and women participate in resistance training at a much lower rate than boys and men, ${ }^{40}$ and this gap is associated with strong gendered expectations of how a woman's body is 'supposed' to look and the gender typing of weightlifting as masculine. ${ }^{23} 42-45$

Some authors suggest sex-specific training programmes are required to improve the effectiveness and uptake of prevention programmes. ${ }^{46}$ However, because of the traditional sexbased approach to studying ACL injury, the need for these programmes is largely based on perceived biological, unchangeable differences. In the wider gender and health literature, there is increasing recognition that sex and gender are 'entangled'that is, the biological and the social influence each other in ways that are not always empirically discernible but are theoretically plausible. ${ }^{47}$ To date, gender has not been considered in concert with sex when studying ACL injury prevention, despite the plausibility that they are both contributing to injury risk.

\section{Injury models}

Mention of general societal expectations that contribute to the ACL injury cycle is included in van Mechelen et al's sports injury model $^{48}$; however, studies that use that model and others ${ }^{49} 50$ as a basis for their work tend to largely focus on individualised approaches as the primary method to address injury. In a review which used the Haddon matrix ${ }^{49}$ to describe the target of prevention initiatives for acute sport injuries, the vast majority required changes in behaviour on the part of the individual. Very few injury prevention strategies targeted policies and rules, or the context in which the injury was occurring. ${ }^{51}$ In a recent scoping review of primarily ACL injury studies, Truong et al reported a dearth of studies that considered social and contextual factors at time of injury and in recovery. ${ }^{6}$ Further, consideration of gendered factors was superficial, with only a small subset of studies reporting aspects of 'masculine sport culture' and a 'no pain no gain' approach to risk-taking. Updates to the original injury models ${ }^{48-50}$ have been proposed which emphasise a more biosocial approach ${ }^{53}$ but they have not included gendered factors specifically.

Recognising that sports injuries do not fit a traditional causeand-effect model, Meeuwisse et al presented a multifactorial, cyclical model outlining how risk factors need to be considered in the manner in which they interact in different ways for different athletes in different settings to bring about an injury. ${ }^{19}$ The authors described how an athlete possesses predisposing traits, which when influenced by external factors and exposed to an inciting event during training or competition, can lead to injury. They state that clinicians and researchers tend to focus on the events at the moment of injury (in the case of non-contact ACL injury, an upright body position with knee valgus), since it is very visible and real to both the practitioner and the athlete. The more remote contributors (eg, why girls and women may lack the strength to avoid the risky position) are rarely considered.

Bekker and Clark agree, and argue that because "injuries are influenced by interactions between people, the physical environment and the social environment", sport injury prevention research needs to adopt a more complex approach. ${ }^{54}$ However, while there is consensus that ACL injury risk is multifactorial, and emerges from a complex 'web of determinants', the discussion continues to remain largely within the confines of an individual's sex-linked biology. ${ }^{55}$ There has been little consideration of the larger sociocultural influences acting on coaches, parents and athletes which may contribute to increased injury risk. ${ }^{56}$ The role of gender, a social construct which is present from the moment we are born, is conspicuously missing from the ACL injury discussion. Therefore, we propose the addition of gender as a "pervasive developmental environment"18 as a new theoretical overlay to Meeuwisse et al's ACL injury model, which can influence and interact with previously identified risk factors throughout the ACL injury cycle (figure 1).

\section{UPDATING THE ACL INJURY PARADIGM}

"bodies tell stories about-and cannot be studied divorced fromthe conditions of our existence ${ }^{, 57}$

The current paradigm for ACL injury displaces bodies from the conditions of our existence, instead focusing heavily on biomechanical explanations, as if our muscles and joints are not impacted by the weight of our life experiences. ${ }^{58}$ To reimagine the approach to ACL injury, we draw on social epidemiological theories of embodiment to conceptualise how social conditions can be materially borne out in the body. ${ }^{47} 57-59$ The addition of gender as an environmental factor in the ACL injury model (figure 1) moves us toward a more dynamic consideration of sex/ gender in ACL injury research. To do this, we draw specifically on Cheslack-Postava and Jordan-Young's formulation of gender as a "pervasive developmental environment," which conceives of human development as "a 'looping process' in which gender is a critical, ongoing factor." 18 This allows us to question the higherorder processes and structures in sporting environments that plausibly differ, purposefully or not, on the basis of sex/gender. Our proposal disrupts the primacy of sex-based explanations of ACL injury and instead suggests that we start from a point of assuming that both biological and social factors are at play. We 


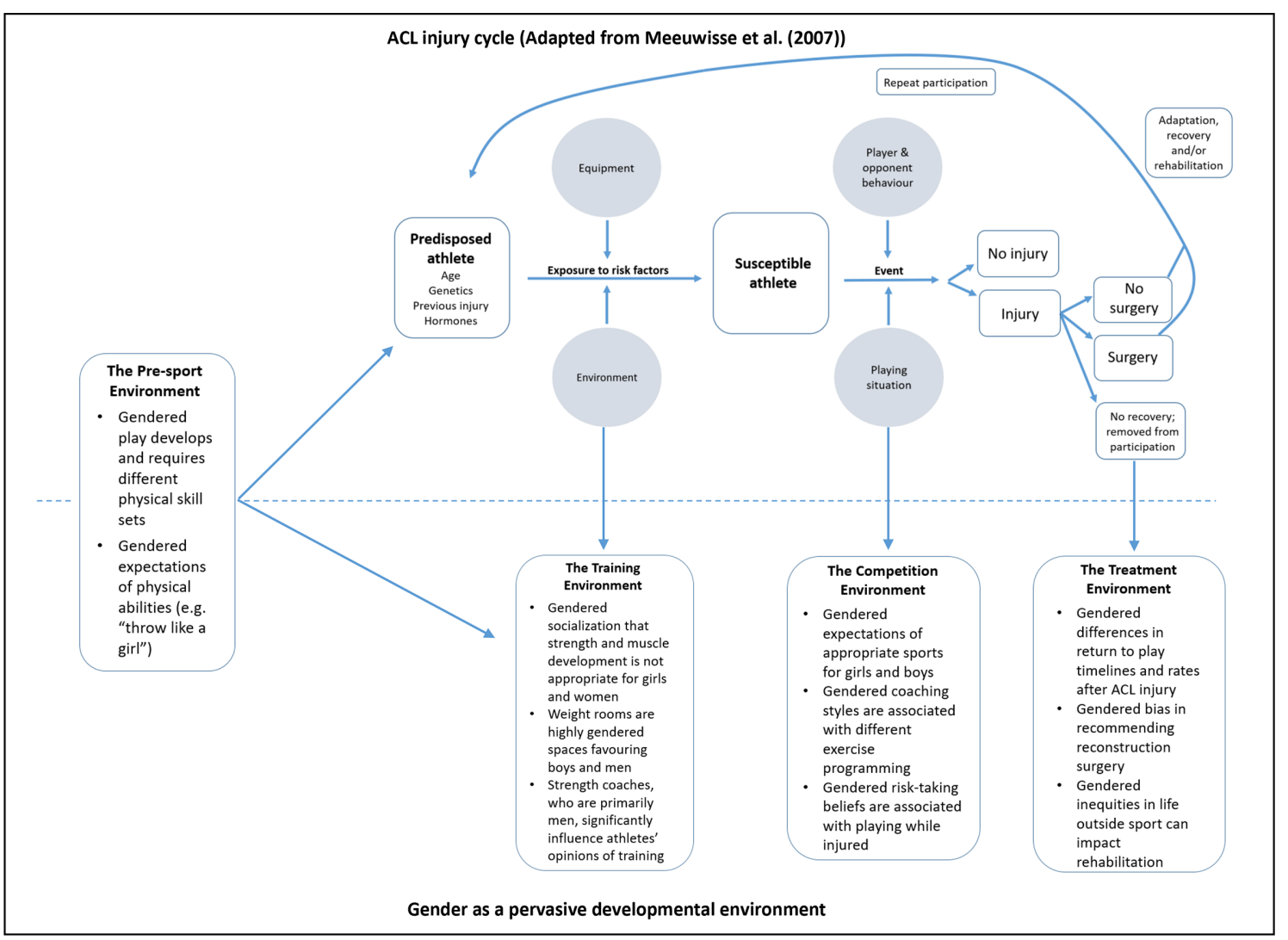

Figure 1 Gender as a pervasive developmental environment in the ACL injury cycle. This figure illustrates how integrating gender as a pervasive developmental environment shaping the context of $A C L$ injury risk expands the traditional ACL injury cycle (based on Meeuwisse et al). Key examples from the presport, training, competition and treatment environments illustrate how gendered processes can lead to susceptibilities in girls and women. ACL, anterior cruciate ligament.

take up Springer et al's call that "this entanglement should be theorised, modelled and assumed until proven otherwise." ${ }^{47}$

As Krieger says, "we live embodied"; that is, "we, like any living organism, literally incorporate, biologically, the world in which we live, including our societal and ecological circumstances." ${ }^{57}$ From this perspective, ACL injury can be conceived, at least in part, as a biological manifestation of cumulative exposure to exogenous social (read: gendered, racialised, etc) conditions that render the body susceptible. This repositions biology from being the sole, central cause of ACL injury (ie, female biomechanics are more prone to injury) to overlaying and making explicit the influence of exposure to gendered processes over the lifecourse and playcourse. Our addition of gender to the ACL injury model illustrates some potential pathways through which the gendered conditions of society and sport function to make girls' and women's bodies 'risky'. Furthermore, embracing the possibility for dynamic processes interconnecting sex and gender embeds potential for the ACL injury model to be inclusive beyond the sex binary.

Our gendered environmental approach offers additional explanations for the sex/gender disparity in ACL injury rates, and opens up new avenues of research. Our goal is to raise a series of possibilities for plausible explanations for the ACL injury rate disparity that focus on gendered influences, which can push us to expand our approach to ACL injury research, prevention and treatment. We present examples of where gendered influences may occur related to four developmental environments surrounding an athlete: (1) the presport environment, (2) the training environment, (3) the competition environment and (4) the treatment environment (figure 1).

\section{The presport environment}

The material effects of gendered socialisation on the body can potentially shape susceptibilities in the bodies of girls and women before even entering sporting environments. Particularly prescient is Iris Marion Young's iconic essay that explored the concept 'throwing like a girl' to make the case as to how gender socialisation manifests in bodily comportment and spatial mobility ${ }^{60}$ From birth, gendered parenting occurs implicitly by, for example, purchasing different toys or allowing greater independent mobility for boys versus girls. ${ }^{61}{ }^{62}$ Exposure to different experiences during infancy and childhood requires and develops differential physical skill sets which could manifest as altered movement patterns in sport later in life. ${ }^{63}$ Gendered expectations that could affect physical development are further illustrated in a study which found that mothers underestimated the crawling abilities of their daughters, but overestimated the abilities of their sons. ${ }^{64}$ These types of implicit experiences and expectations are pervasive, extend to other environments such as schools, and result in 'environmentally induced' physical abilities $^{65}$ and a motor control gender gap. ${ }^{66}$ The impact of possibly rendering the female-presenting body more susceptible to injury prior to even entering the realm of sport is unknown.

\section{The training environment}

Resistance training is an important component for effective ACL injury prevention, ${ }^{38}$ but there is significant evidence 
that participating in resistance training and increasing muscle mass is not seen as socially acceptable or desirable for girls and women, ${ }^{23} 42-4567$ even as new body ideals such as a 'thin muscular' physique emerge. ${ }^{68}$ Women competing in collegiate sports report constantly having to negotiate issues of muscularity and femininity in resistance training environments. ${ }^{6970}$ Although these athletes recognise the benefits to their sport performance, they tend to hold back during training sessions because of concerns of becoming too 'bulky' and muscular. The weight room environment itself is a highly gendered space where many women feel uncomfortable, ${ }^{23-26} 42-45$ and even materially shrink their consumption of time, space and equipment in response. ${ }^{23}$ Strength and conditioning ( \& C ) coaches play a significant role in creating the training environment for athletes, and strongly influence athletes' opinions of resistance training. ${ }^{2669}$ Because S \& C coaches are overwhelmingly men, ${ }^{71}$ women are likely to continue to feel that weight rooms are not a place for them. These gendered training dynamics may be a significant contributor to the ACL injury rate disparity between women and men, given the well-documented lower resistance training participation rates among girls and women compared with boys and men, ${ }^{40} 41$ and the importance of that activity for effective ACL injury prevention programmes. ${ }^{38}$

Some authors have suggested that sex-specific training programmes may be required because injury risk factors ${ }^{46}$ or athlete motivations and abilities ${ }^{72}$ may differ between girls/ women and boys/men. However, many of the assumptions behind these perceived differences are based on a belief that they are biological and unchangeable, when in fact they are heavily shaped by modifiable gendered factors. ${ }^{17}$ Sex-specific programming may also knowingly or unknowingly embed and perpetuate sexed/gendered stereotypes and differences that disadvantage girls and women. Before we assume that training for ACL injury prevention needs to be different for girls/women and boys/men, we need information as to the gendered environments that already exist. It is likely that training is already different, but in a way that disadvantages girls/women. As far as we are aware, no literature exists regarding how ACL injury prevention programmes, or resistance training in general, are communicated or presented to girls/women and boys/men. Men and women coaches have been found to differ in the types of stretching activities they programme for their athletes during warm-up. ${ }^{73}$ It is plausible that these gendered coaching actions could extend to ACL injury prevention efforts, with unknown effects on the athlete. Are there differences in how the coaches explain, support, and interact with their athletes during the training programme, depending on the sex/gender of the coach or athletes? Are the expectations and exercise standards different? Perhaps sex-specific injury prevention training programmes are not required-perhaps we just need to better understand the societal influences already at play, and ensure equitable delivery of interventions so that all athletes benefit.

Some authors ${ }^{74}$ mention training background as an influencer on ligament strength; and other soft tissue and bony structural characteristics, such as the size of the ACL and femoral notch shape, are supported as risk factors for injury. ${ }^{75} 76$ These are typically categorised as intrinsic, non-modifiable, anatomical risk factors ${ }^{77}$; however, bone, joint and muscle loading that may appear to manifest sex differences could also be a result of gendered processes, ${ }^{58}$ and gender is an extrinsic factor created by society. Loading anatomical structures causes changes to their material properties. The principles of tissue adaptability state that soft tissue and bone will adapt and model according to the forces with which they are subjected, and is the cornerstone of preventative and rehabilitative exercise programming. ${ }^{78}$ There is some evidence to suggest that the structure of the ACL can change with loading ${ }^{79} 80$, and a recent study found a significant relationship between quadriceps muscle volume and ACL volume $;^{81}$ however, the consequences and implications are unknown. Anatomical risk factors for ACL injury may very well include both a biological and a societal influence (ie, the 'entanglement' of sex/gender).

\section{The competition environment}

By its very binary nature, sport places girls/women and boys/men in different playing situations. It may appear superficially that they are divided in most sports strictly based on sex; however, gendered expectations of acceptable activities strongly influence sport opportunities and experiences. For example, American football is ubiquitous across North America up to the professional level for men, but hardly exists for women. ${ }^{82}$ Bodychecking is not allowed in women's ice hockey, while it is a large part of the men's game. As of 2021, women in Australian Rules football play quarters that are $5 \mathrm{~min}$ shorter compared with the men's league, and tennis matches for women are capped at three sets, and for men at five sets. Men comprise a tiny fraction of netball players in the UK, which is classified as a non-contact sport. These are clear examples of how sex/gender are 'entangled' to produce diverse sport experiences for women and men, which we argue must factor into ACL injury risk.

Another example of how gender can affect the competition environment is through athlete behaviour and sport culture. Player and opponent behaviour can influence whether an injury occurs or not. ${ }^{48}$ Risk-taking behaviour and winning are traditionally viewed as masculine traits and are highly valued in sport environments, but can lead to injury. ${ }^{83}$ Girls and women may adopt hyper-masculine traits as a way to 'fit in' to sport, further compounding an already complicated set of risk factors for ACL injury. This may have material consequences. For example, women athletes who conformed more strongly to these masculine traits were more likely to continue to play with concussion symptoms. ${ }^{83}$ Since cognitive function has been associated with ACL injury risk, ${ }^{84}$ this demonstrates how gender could be contributing to the injury rate disparity between women and men. However, despite the link between injury and the typically hyper-masculine expectations and behaviour valued in sport, only 2 of 77 studies found in a scoping review of non-biological factors that could affect recovery from knee injury included contextual elements such as sport culture. ${ }^{6}$

\section{The treatment environment}

We need to consider gender as a potential influencer right through to the postinjury, rehabilitation and return to sport portions of the ACL injury cycle. Examples in the literature show the pervasiveness of gendered assumptions in medical interventions and treatment, and the negative effects they can have on women's health. ${ }^{8586}$ Compared with men, after ACL reconstruction, women have greater knee laxity, lower patient reported knee function, less chance of returning to sport, and a more frequent need for revision surgery. ${ }^{87}$ Comparing postsurgical outcomes between men and women again assumes that their preinjury status, rehabilitation and subsequent training environments are equivalent. Could it be that men and women experience rehabilitation differently due to biases in healthcare settings? The sex and/or gender of the athlete, as well as the sex and/or gender of all the healthcare professionals the athlete comes into contact with (ie, emergency room 
physician, referring physician, surgeon, physical therapists) from the onset of injury to return to sport, may be important. Since systemic change is not solved at the clinical level by individual practitioners, this affords us an opportunity to look more broadly and use interdisciplinary, multilevel approaches to the ACL injury problem.

Like previous work which found surgical treatment options were more frequently offered to men, ${ }^{85}$ there is evidence of a similar institutional gender bias in recommending ACL reconstruction surgery more often to boys $/$ men. ${ }^{88}$ However, if they do have ACL reconstruction, women are more likely to require revision surgery. ${ }^{87}$ Women subsequently experience a higher incidence of total knee arthroplasty within 20 years after rupturing their ACL. ${ }^{89}$ Rehabilitation from an ACL injury, whether surgically repaired or not, requires dedication to a training programme for an extended period of time. Current evidence suggests the chance of reinjury is significant if athletes do not wait at least 9 months to return to sport. ${ }^{90}$ Given that men and women experience training and competition environments differently, what implications does that have for rehabilitating from an ACL injury? Boys and men return to sport more quickly than girls and women after ACL injury, ${ }^{4}$ which could be a result of gendered expectations related to a masculine sport culture where playing through pain and winning at all costs is valued. ${ }^{83}$ But it could also relate to the types of training environments that women and men experience and have access to during rehabilitation. Likewise, the wider gendered context of women's and men's lives (eg, inequities in familial and domestic labour) ${ }^{91}$ may create different opportunities and constraints for women and men to complete effective rehabilitation. Until the approach to studying ACL injury transforms and includes consideration of gendered factors, we will continue to have an incomplete picture of ACL injury and the disadvantages to girls and women will endure.

\section{Going forward: applying a gendered environmental lens}

If we revisit table 1 through our gendered environmental lens, we can see how most of the injury risk factors identified as intrinsic could be strongly influenced by social and cultural expectations of what girls/women and boys/men should be and do. We suggest, in agreement with Cameron, ${ }^{92}$ that viewing risk factors as modifiable or nonmodifiable is more useful to front-line practitioners who are working to decrease injury risk. This perspective also suggests that we can address a factor by modifying the environment, not just the individual. Through Marmot's work on the Social Determinants of Health, ${ }^{93}$ we now know that understanding and acting on upstream social and contextual factors is vital in improving individual and population health. In the same way that these contemporary understandings have shown that it is racism, not race that influences health and injury outcomes, ${ }^{94} 95$ we argue here that it is sexism (positioned as a "structural phenomenon, perpetuated by social institutions, policies and broader cultural mores"), ${ }^{96}$ not simply sex that plays a role in ACL injury outcomes. In this way, gendered experiences (together with class, disability, sexuality, racism and other social structures) matter for shaping girls' and women's sport participation and injury outcomes. Rather than positioning sex or gender as intrinsic risk factors (as is the norm in a field where cisgender male whiteness is the default), ${ }^{9798}$ it is worth considering them as also extrinsic. Effects observed at the individual level can be understood as outcomes of ways that the social and material contexts of sport condition sporting bodies. Moving beyond

\section{Box 1 Key definitions}

\section{Sex and gender}

Sex refers to a complex blend of physical and physiological characteristics (eg, hormones, genes, anatomy), while gender refers to identities, roles and structures that are formed by society, which may or may not align with sex-neither of which is binary. ${ }^{20}$

\section{Sex/gender}

Sex/gender is increasingly being used as a term to recognise the empirical and conceptual 'entanglement' of biological and social factors in expressions of sex and gender. ${ }^{47}$ It acknowledges the dynamic processes and interactions through which "body-based characteristics... are shaped by gendered social interactions". 101102

\section{What is already known?}

The anterior cruciate ligament injury rate disparity between girls/women and boys/men has not changed in over 20 years.

- The approach to addressing the injury rate disparity and establishing effective prevention and treatment programmes is multifactorial and complex.

\section{What are the new findings?}

- Gendered factors present in the presport, training, competition and rehabilitation environments have not been explicitly included in anterior cruciate ligament injury models to date.

- Gender, as an extrinsic social construct, likely influences many of the risk factors previously considered intrinsic to the athlete.

a biological starting point to incorporate both biology and society as possible influences on ACL injury risk can lead to new advances in the field.

\section{CONCLUSION}

By overlaying gender as a pervasive developmental environment onto an existing ACL injury model, we are urging researchers and clinicians to consider and include gendered factors when attempting to address the higher injury rate in girls and women. The ACL injury cycle requires a holistic and intersectional approach; for example, we cannot simply tell girls/women to 'get stronger' to reduce injury risk if society and the environment do not support those types of activities for everyone. Work in public health tells us that prevention efforts are most effective when broader society and cultural norms are targeted, rather than placing the burden on individual people to change their behaviour. ${ }^{99100}$ Previous authors have suggested a real need to understand the broader factors at play, ${ }^{52} 53$ yet there has been a curious and alarming absence of gender in the conversation, given that the higher rate of ACL injury in girls and women reported in the 1990s caused an explosion of research in the area. Our hope is that positioning gender as a pervasive developmental environment in the ACL injury cycle will spur new, interdisciplinary research 
that will further our understanding of the complexities of ACL injury. Over 20 years of research has failed to decrease the ACL injury rate in girls and women; it is time to take a different approach.

Twitter Joanne L Parsons @J_ParsonsUofM, Stephanie E Coen @steph_coen and Sheree Bekker@shereebekker

Acknowledgements A sincere thank you to the reviewers, including Dr. Aaron Fox, who generously gave their time during the COVID-19 pandemic to provide remarkably valuable and helpful feedback.

Contributors JLP conceptualised the initial idea for the paper and outlined the current state of the ACL injury literature. SEC placed the new approach within existing theories of the embodiment of gender and health. JLP and SEC jointly developed the gendered environmental approach to ACL injury. SB contributed an intersectional lens, and an overall critical review of the paper. All authors approved the final version of the manuscript.

Funding The authors have not declared a specific grant for this research from any funding agency in the public, commercial or not-for-profit sectors.

Competing interests None declared.

Patient consent for publication Not required.

Provenance and peer review Not commissioned; externally peer reviewed.

\section{ORCID iDs}

Joanne L Parsons http://orcid.org/0000-0003-1022-6364

Stephanie E Coen http://orcid.org/0000-0003-3939-8792

Sheree Bekker http://orcid.org/0000-0003-0161-6280

\section{REFERENCES}

1 Lindenfeld TN, Schmitt DJ, Hendy MP, et al. Incidence of injury in indoor soccer. Am J Sports Med 1994;22:364-71.

2 Arendt EA, Agel J, Dick R. Anterior cruciate ligament injury patterns among collegiate men and women. J Athl Train 1999;34:86-92.

3 Shultz SJ, Schmitz RJ, Cameron KL, et al. Anterior cruciate ligament research retreat VIII summary statement: an update on injury risk identification and prevention across the anterior cruciate ligament injury continuum, March 14-16, 2019, Greensboro, NC. J Athl Train 2019;54:970-84.

4 Ardern CL, Taylor NF, Feller JA, et al. Fifty-five per cent return to competitive sport following anterior cruciate ligament reconstruction surgery: an updated systematic review and meta-analysis including aspects of physical functioning and contextual factors. Br I Sports Med 2014;48:1543-52.

5 Ardern CL, Glasgow P, Schneiders A, et al. 2016 consensus statement on return to sport from the First World Congress in Sports Physical Therapy, Bern. Br I Sports Med 2016;50:853-64

6 Truong LK, Mosewich AD, Holt CJ, et al. Psychological, social and contextual factors across recovery stages following a sport-related knee injury: a scoping review. $\mathrm{Br} J$ Sports Med 2020:54:1149-56.

7 Sanders TL, Maradit Kremers H, Bryan AJ, et al. Incidence of anterior cruciate ligament tears and reconstruction: a 21-year population-based study. Am I Sports Med 2016;44:1502-7.

8 Agel J, Rockwood T, Klossner D. Collegiate ACL injury rates across 15 sports: National Collegiate Athletic Association injury surveillance system data update (2004-2005 through 2012-2013). Clin J Sport Med 2016;26:518-23.

9 Montalvo AM, Schneider DK, Yut L, et al. "What's my risk of sustaining an ACL injury while playing sports?" A systematic review with meta-analysis. Br I Sports Med 2019:53:1003-12.

10 Suter LG, Smith SR, Katz JN, et al. Projecting lifetime risk of symptomatic knee osteoarthritis and total knee replacement in individuals sustaining a complete anterior cruciate ligament tear in early adulthood. Arthritis Care Res 2017;69:201-8.

11 Telama R, Yang X, Viikari J, et al. Physical activity from childhood to adulthood: a 21-year tracking study. Am J Prev Med 2005;28:267-73.

12 Guthold R, Stevens GA, Riley LM, et al. Worldwide trends in insufficient physical activity from 2001 to 2016: a pooled analysis of 358 population-based surveys with 1.9 million participants. Lancet Glob Health 2018:6:e1077-86.

13 DeFroda SF, Bokshan SL, Worobey S, et al. Oral contraceptives provide protection against anterior cruciate ligament tears: a national database study of 165,748 female patients. Phys Sportsmed 2019;47:416-20.

14 Muggleton E, Muggleton T. Retrospective analyses must be interpreted cautiously. A reply to 'oral contraceptives provide protection against anterior crucial ligaments tears'. Phys Sportsmed 2019;47:239.

15 Prior J, Whittaker JL, Scott AW. Adolescent combined hormonal contraceptives and surgical repair of anterior cruciate tears: a risky recommendation based on an unproven causal relationship. Phys Sportsmed 2019:47:240-1.

16 Sewell E. Knee crisis growing. Herald Sun, 2019.
17 Fox A, Bonacci J, Hoffmann S, et al. Anterior cruciate ligament injuries in Australian football: should women and girls be playing? You're asking the wrong question. BM Open Sport Exerc Med 2020;6:e000778

18 Cheslack-Postava K, Jordan-Young RM. Autism spectrum disorders: toward a gendered embodiment model. Soc Sci Med 2012;74:1667-74.

19 Meeuwisse WH, Tyreman H, Hagel B, et al. A dynamic model of etiology in sport injury: the recursive nature of risk and causation. Clin I Sport Med 2007;17:215-9.

20 Canadian Institutes of Health Research, Institute of Gender and Health. What is gender? What is sex?2014. Available: http://www.cihr-irsc.gc.ca/e/48642.html

21 Canadian Institutes of Health Research, Institute of Gender and Health. Online training modules: integrating sex \& gender in health research. IGH Learning, 2019. Available: https://cihr-irsc.gc.ca/e/49347.html

22 Renstrom $\mathrm{P}$, Ljungqvist $\mathrm{A}$, Arendt $\mathrm{E}$, et al. Non-Contact $\mathrm{ACL}$ injuries in female athletes: an international Olympic Committee current concepts statement. $\mathrm{Br} J$ Sports Med 2008:42:394-412.

23 Coen SE, Rosenberg MW, Davidson J. "It's gym, like g-y-m not J-i-m": Exploring the role of place in the gendering of physical activity. Soc Sci Med 2018;196:29-36.

24 Coen SE, Davidson J, Rosenberg MW. Where is the space for continuum?' Gyms and the visceral "stickiness" of binary gender. Qual Res Sport Exerc Health 2020:1-17.

25 Coen SE, Davidson J, Rosenberg MW. Towards a critical geography of physical activity: emotions and the gendered boundary-making of an everyday exercise environment. Trans Inst Br Geogr 2020;45:313-30.

26 Parsons JL, Ripat J. Understanding the experiences of girls using a high schoo weight room. PHE Journal 2020;86.

27 Beunen G, Malina RM. Growth and physical performance relative to the timing of the adolescent spurt. Exerc Sport Sci Rev 1988;16:503-40.

28 Hewett TE, Myer GD, Ford KR. Decrease in neuromuscular control about the knee with maturation in female athletes. J Bone Joint Surg Am 2004;86:1601-8.

29 Olsen O-E, Myklebust G, Engebretsen L, et al. Injury mechanisms for anterior cruciate ligament injuries in team handball: a systematic video analysis. Am J Sports Med 2004:32:1002-12.

30 Markolf KL, Burchfield DM, Shapiro MM, et al. Combined knee loading states that generate high anterior cruciate ligament forces. J Orthop Res 1995;13:930-5.

31 Shultz SJ, Schmitz RJ, Benjaminse A, et al. ACL research retreat VII: an update on anterior cruciate ligament injury risk factor identification, screening, and prevention. J Athl Train 2015:50:1076-93.

32 Holden S, Boreham C, Delahunt E. Sex differences in landing biomechanics and postural stability during adolescence: a systematic review with meta-analyses. Sports Med 2016;46:241-53.

33 Quatman $\mathrm{CE}$, Ford $\mathrm{KR}$, Myer GD, et al. Maturation leads to gender differences in landing force and vertical jump performance: a longitudinal study. Am I Sports Med 2006;34:806-13.

34 Gamada K, Kubota S. The mechanism of non-contact anterior cruciate ligament injury in female athletes: is the injury mechanism different between the genders? Int J Phys Med Rehabil 2014:02:246-63.

35 Owusu-Akyaw KA, Kim SY, Spritzer CE, et al. Determination of the position of the knee at the time of an anterior cruciate ligament rupture for male versus female patients by an analysis of bone bruises. Am J Sports Med 2018;46:1559-65.

36 Webster KE, Hewett TE. Meta-Analysis of meta-analyses of anterior cruciate ligament injury reduction training programs. J Orthop Res 2018;36:2696-708.

37 Myklebust G, Skjølberg A, Bahr R. ACL injury incidence in female handball 10 years after the Norwegian ACL prevention study: important lessons learned. Br J Sports Med 2013:47:476-9.

38 Sugimoto D, Myer GD, Foss KDB, et al. Specific exercise effects of preventive neuromuscular training intervention on anterior cruciate ligament injury risk reduction in young females: meta-analysis and subgroup analysis. $\mathrm{Br} J \mathrm{Sports} \mathrm{Med}$ 2015;49:282-9

39 Khayambashi K, Ghoddosi N, Straub RK, et al. Hip muscle strength predicts noncontact anterior cruciate ligament injury in male and female athletes. $A m J$ Sports Med 2016:44:355-61.

40 Bennie JA, De Cocker K, Teychenne MJ, et al. The epidemiology of aerobic physical activity and muscle-strengthening activity guideline adherence among 383,928U.S. adults. Int I Behav Nutr Phys Act 2019;16:34

41 Caspersen CJ, Pereira MA, Curran KM. Changes in physical activity patterns in the United States, by sex and cross-sectional age. Med Sci Sports Exerc 2000;32:1601-9.

42 Dworkin SL. "Holding Back": negotiating a glass ceiling on women's muscula strength. Sociol Perspect 2001;44:333-50.

43 Brace-Govan J. Weighty matters: control of women's access to physical strength. Sociol Rev 2004;52:503-31.

44 Dworkin SL. A woman's place is in the... cardiovascular room?? Gender relations, the body, and the gym. Athletic intruders: Ethnographic research on women, culture, and exercise 2003:131-58.

45 Salvatore J, Marecek J. Gender in the gym: evaluation concerns as barriers to women's weight lifting. Sex Roles 2010;63:556-67.

46 Lin CY, Casey E, Herman DC, et al. Sex differences in common sports injuries. PM\&R 2018;10:1073-82. 
47 Springer KW, Mager Stellman J, Jordan-Young RM. Beyond a catalogue of differences: a theoretical frame and good practice guidelines for researching sex/ gender in human health. Soc Sci Med 2012;74:1817-24.

48 van Mechelen W, Hlobil H, Kemper HC. Incidence, severity, aetiology and prevention of sports injuries. A review of concepts. Sports Med 1992;14:82-99.

49 Haddon W. On the escape of tigers: an ecologic note. Am J Public Health Nations Health 1970;60:2229-34.

50 Meeuwisse WH. Assessing causation in sport injury: a multifactorial model. Clin J Sport Med 1994;4:166-70.

51 Vriend I, Gouttebarge V, Finch CF, et al. Intervention strategies used in sport injury prevention studies: a systematic review identifying studies applying the Haddon matrix. Sports Med 2017:47:2027-43.

52 Bolling C, van Mechelen W, Pasman HR, et al. Context matters: revisiting the first step of the 'Sequence of Prevention' of sports injuries. Sports Med 2018:48:2227-34.

53 Finch CF, Donaldson A. A sports setting matrix for understanding the implementation context for community sport. Br J Sports Med 2010;44:973-8.

54 Bekker S, Clark AM. Bringing complexity to sports injury prevention research: from simplification to explanation. Br J Sports Med 2016:50:1489-90.

55 Bittencourt NFN, Meeuwisse WH, Mendonça LD, et al. Complex systems approach for sports injuries: moving from risk factor identification to injury pattern recognition-narrative review and new concept. Br J Sports Med 2016;50:1309-14.

56 Wiese-Bjornstal DM. Psychology and socioculture affect injury risk, response, and recovery in high-intensity athletes: a consensus statement. Scand J Med Sci Sports 2010;20:103-11

57 Krieger N. Embodiment: a conceptual glossary for epidemiology. J Epidemiol Community Health 2005;59:350-5.

58 Fausto-Sterling A. The bare bones of sex: part 1—sex and gender. Signs 2005;30:1491-527

59 Krieger N. Genders, sexes, and health: what are the connections - and why does it matter? Int J Epidemiol 2003;32:652-7.

60 Young IM. Throwing like a girl: a phenomenology of feminine body comportment motility and spatiality. Hum Stud 1980;3:137-56.

61 Ghekiere A, Deforche B, Carver A, et al. Insights into children's independent mobility for transportation cycling-Which socio-ecological factors matter? J Sci Med Sport 2017;20:267-72

62 McDonald NC. Is there a gender gap in school travel? An examination of US children and adolescents. J Transp Geogr 2012;20:80-6.

63 Mesman J, Groeneveld MG. Gendered parenting in early childhood: subtle but unmistakable if you know where to look. Child Dev Perspect 2018;12:22-7.

64 Mondschein ER, Adolph KE, Tamis-LeMonda CS. Gender bias in mothers' expectations about infant crawling. J Exp Child Psychol 2000;77:304-16.

65 Thomas JR, French KE. Gender differences across age in motor performance: a metaanalysis. Psychol Bull 1985;98:260-82.

66 Barnett LM, van Beurden E, Morgan PJ, et al. Gender differences in motor skill proficiency from childhood to adolescence: a longitudinal study. Res Q Exerc Sport 2010;81:162-70.

67 McCabe MP, James T. Strategies to change body shape among men and women who attend fitness centers. Asia Pac J Public Health 2009;21:268-78.

68 Bozsik F, Whisenhunt BL, Hudson DL, et al. Thin is in? Think again: the rising importance of muscularity in the thin ideal female body. Sex Roles 2018;79:609-15.

69 Roth RI, Knapp BA. Gender negotiations of female collegiate athletes in the strength and conditioning environment. WSPAJ 2017;25:50-9.

70 Beckner BN, Record RA. Navigating the thin-ideal in an athletic world: influence of coach communication on female athletes' body image and health choices. Health Commun 2016:31:364-73.

71 O'Malley LM, Greenwood S. Female coaches in strength and conditioning — why so few? Strength Cond J 2018;40:40-8.

72 Reynolds ML, Ransdell LB, Lucas SM, et al. An examination of current practices and gender differences in strength and conditioning in a sample of varsity high school athletic programs. J Strength Cond Res 2012;26:174-83.

73 Judge LW, Avedesian JM, Bellar DM, et al. Pre- and post-activity stretching practices of collegiate soccer coaches in the United States. Int J Exerc Sci 2020;13:260.

74 Bahr R, Krosshaug T. Understanding injury mechanisms: a key component of preventing injuries in sport. Br J Sports Med 2005;39:324-9.

75 Chandrashekar N, Slauterbeck J, Hashemi J. Sex-based differences in the anthropometric characteristics of the anterior cruciate ligament and its relation to intercondylar notch geometry: a cadaveric study. Am J Sports Med 2005;33:1492-8.

76 Zhang C, Xie G, Fang Z, et al. Assessment of relationship between three dimensional femoral notch volume and anterior cruciate ligament injury in Chinese Han adults: a retrospective MRI study. Int Orthop 2019;43:1231-7.
77 Beynnon BD, Sturnick DR, Argentieri EC, et al. A sex-stratified multivariate risk factor model for anterior cruciate ligament injury. J Ath/ Train 2015;50:1094-6.

78 Mueller MJ, Maluf KS. Tissue adaptation to physical stress: a proposed "Physical Stress Theory" to guide physical therapist practice, education, and research. Phys Ther 2002;82:383-403.

79 Hayashi K. Biomechanical studies of the remodeling of knee joint tendons and ligaments. J Biomech 1996;29:707-16.

80 Myrick KM, Voss A, Feinn RS, et al. Effects of season long participation on ACL volume in female intercollegiate soccer athletes. J Exp Orthop 2019;6:12.

81 Shultz SJ, Schmitz RJ, Kulas AS, et al. Quadriceps muscle volume positively contributes to ACL volume. J Orthop Res 2021. doi:10.1002/jor.24989. [Epub ahead of print: 28 Jan 2021].

82 de la Cretaz B. More girls are playing football. is that progress? The New York Times, 2018February 2.

83 Kroshus E, Baugh CM, Stein CJ, et al. Concussion reporting, sex, and conformity to traditional gender norms in young adults. J Adolesc 2017;54:110-9.

84 Swanik CB, Covassin T, Stearne DJ, et al. The relationship between neurocognitive function and noncontact anterior cruciate ligament injuries. Am J Sports Med 2007:35:943-8.

85 Borkhoff CM, Hawker GA, Kreder HJ, et al. The effect of patients' sex on physicians' recommendations for total knee arthroplasty. Can Med Assoc J 2008;178:681-7.

86 Bairey Merz CN, Andersen HS, Shufelt CL. Gender, cardiovascular disease, and the sexism of obesity. J Am Coll Cardiol 2015;66:1958-60

87 Tan SHS, Lau BPH, Khin LW, et al. The importance of patient sex in the outcomes of anterior cruciate ligament reconstructions: a systematic review and meta-analysis. Am J Sports Med 2016;44:242-54.

88 Collins JE, Katz JN, Donnell-Fink LA, et al. Cumulative incidence of ACL reconstruction after $A C L$ injury in adults: role of age, sex, and race. Am J Sports Med 2013:41:544-9.

89 Abram SGF, Judge A, Khan T, et al. Rates of knee arthroplasty in anterior cruciate ligament reconstructed patients: a longitudinal cohort study of 111,212 procedures over 20 years. Acta Orthop 2019;90:568-74.

90 Grindem H, Snyder-Mackler L, Moksnes H, et al. Simple decision rules can reduce reinjury risk by $84 \%$ after $\mathrm{ACL}$ reconstruction: the Delaware-Oslo $\mathrm{ACL}$ cohort study. Br J Sports Med 2016:50:804-8.

91 Office for National Statistics. Women shoulder the responsibility of 'unpaid' work, 2016. Available: https://www.ons.gov.uk/employmentandlabourmarket/ peopleinwork/earningsandworkinghours/articles/womenshouldertheresponsibilityof unpaidwork/2016-11-10 [Accessed 22 Jul 2020].

92 Cameron KL. Commentary: time for a paradigm shift in conceptualizing risk factors in sports injury research. J Athl Train 2010;45:58-60.

93 Marmot M, Wilkinson R. Social determinants of health. Oxford University Press, 2005.

94 Devakumar D, Selvarajah S, Shannon G, et al. Racism, the public health crisis we can no longer ignore. Lancet 2020;395:e112-3.

95 Krieger N. Measures of racism, sexism, heterosexism, and gender binarism for health equity research: from structural injustice to embodied harm-An ecosocial analysis. Annu Rev Public Health 2020:41:37-62.

96 Manne K. Down girl: the logic of misogyny. Oxford University Press, 2017.

97 Hagstrom AD, Yuwono N, Warton K, et al. Sex bias in cohorts included in sports medicine research. Sports Med 2021;14.

98 Blake $\mathrm{T}$. In the fight for racial justice, the sidelines are no longer an option. $\mathrm{Br} J$ Sports Med 2020;54:1245-6.

99 Lund J, Aarø LE. Accident prevention. Presentation of a model placing emphasis on human, structural and cultural factors. Saf Sci 2004;42:271-324.

100 Glass TA, McAtee MJ. Behavioral science at the crossroads in public health: extending horizons, envisioning the future. Soc Sci Med 2006;62:1650-71.

101 Fausto-Sterling A. Sex/gender: biology in a social world. Routledge, 2012.

102 Fausto-Sterling A, Sung J, Hale M. Embodying gender/sex identity during infancy: a theory and preliminary findings. OSF preprints 2020.

103 Price MJ, Tuca M, Cordasco FA, et al. Nonmodifiable risk factors for anterior cruciate ligament injury. Curr Opin Pediatr 2017;29:55-64

104 Griffin LY, Albohm MJ, Arendt EA, et al. Understanding and preventing noncontact anterior cruciate ligament injuries: a review of the HUNT Valley II meeting, January 2005. Am J Sports Med 2006;34:1512-32.

105 Griffin LY. Prevention of noncontact $A C L$ injuries. Rosemont, Illinois: American Academy of Orthopaedic Surgeons, 2001

106 Shultz SJ, Schmitz RJ, Nguyen A-D. Research Retreat IV: ACL injuries--the gender bias: April 3-5, 2008 Greensboro, NC. J Athl Train 2008;43:530-1.

107 Williams JM, Andersen MB. Psychosocial antecedents of sport injury: Review and critique of the stress and injury model. J App/ Sport Psychol 1998;10:5-25. 